\title{
Enhanced-performance of self-powered flexible quantum dot photodetectors by double hole transport layer structure
}

DOI:

10.1039/C9NR01096C

\section{Document Version}

Accepted author manuscript

Link to publication record in Manchester Research Explorer

Citation for published version (APA):

Shen, T., Binks, D., Yuan, J., Cao, G., \& Tian, J. (2019). Enhanced-performance of self-powered flexible quantum dot photodetectors by double hole transport layer structure. Nanoscale. https://doi.org/10.1039/C9NR01096C

\section{Published in:}

Nanoscale

\section{Citing this paper}

Please note that where the full-text provided on Manchester Research Explorer is the Author Accepted Manuscript or Proof version this may differ from the final Published version. If citing, it is advised that you check and use the publisher's definitive version.

\section{General rights}

Copyright and moral rights for the publications made accessible in the Research Explorer are retained by the authors and/or other copyright owners and it is a condition of accessing publications that users recognise and abide by the legal requirements associated with these rights.

\section{Takedown policy}

If you believe that this document breaches copyright please refer to the University of Manchester's Takedown Procedures [http://man.ac.uk/04Y6Bo] or contact uml.scholarlycommunications@manchester.ac.uk providing relevant details, so we can investigate your claim.

\section{OPEN ACCESS}



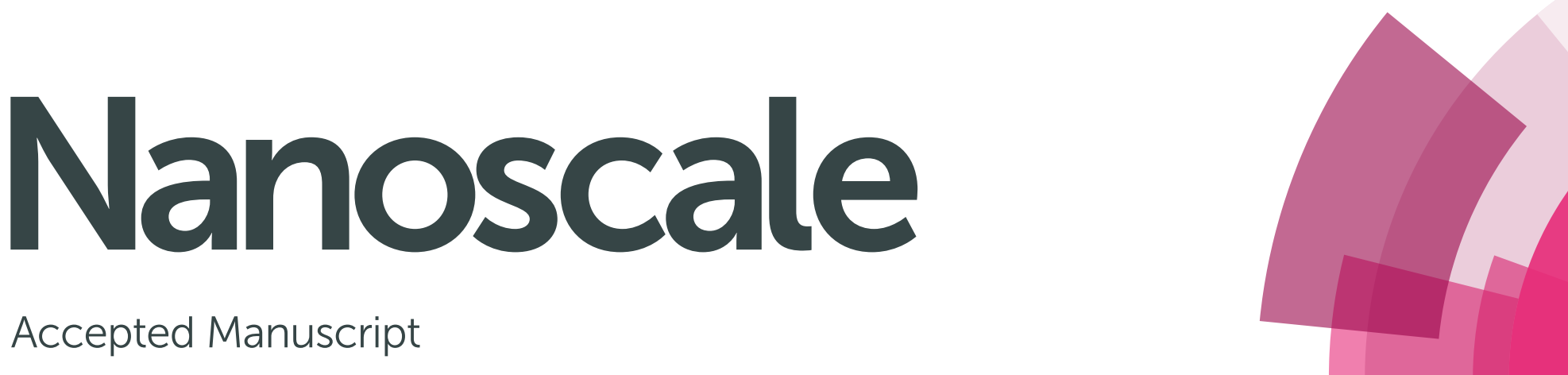

\section{Accepted Manuscript}

This article can be cited before page numbers have been issued, to do this please use: T. Shen, D. Binks, J. Yuan, G. Cao and J. Tian, Nanoscale, 2019, DOI: 10.1039/C9NR01096C.

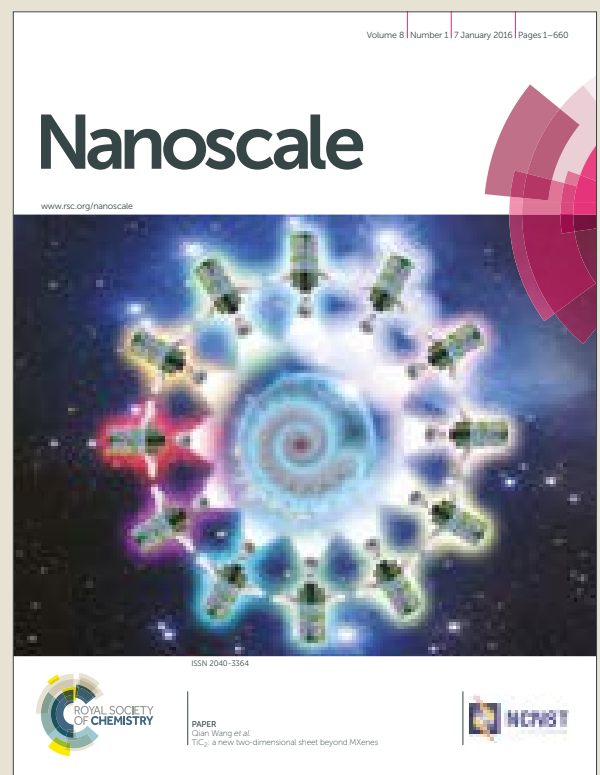

This is an Accepted Manuscript, which has been through the Royal Society of Chemistry peer review process and has been accepted for publication.

Accepted Manuscripts are published online shortly after acceptance, before technical editing, formatting and proof reading. Using this free service, authors can make their results available to the community, in citable form, before we publish the edited article. We will replace this Accepted Manuscript with the edited and formatted Advance Article as soon as it is available.

You can find more information about Accepted Manuscripts in the author guidelines.

Please note that technical editing may introduce minor changes to the text and/or graphics, which may alter content. The journal's standard Terms \& Conditions and the ethical guidelines, outlined in our author and reviewer resource centre, still apply. In no event shall the Royal Society of Chemistry be held responsible for any errors or omissions in this Accepted Manuscript or any consequences arising from the use of any information it contains. 


\title{
Journal Name
}

\section{Enhanced-performance of self-powered flexible quantum dot photodetectors by double hole transport layer structure}

Received 00th January 20xx, Accepted 00th January 20xx

DOI: $10.1039 / x 0 \times x 00000 x$

www.rsc.org/

\author{
Ting Shen ${ }^{a}$, David Binks ${ }^{b}$, Jifeng Yuan ${ }^{a}$, Guozhong Cao ${ }^{c}$, Jianjun Tian ${ }^{a *}$
}

\begin{abstract}
The usefulness of self-powered quantum dot (QD) photodetectors is increased if they are fabricated on flexible substrates. However, the performance of such photodetectors is typically significantly worse than similar devices fabricated on glass substrates due to poor charge transport performance. Here, a novel flexible self-powered $\mathrm{CdSe}_{\mathrm{x}} \mathrm{Te}_{1-\mathrm{x}} \mathrm{QD}$ photodetector with a double hole transport layer of PEDOT:PSS/ P-TPD has been fabricated, which achieves a performance comparable to that of rigid devices. The energy level of the P-TPD layer matches well with that of the PEDOT:PSS and QD layers, which significantly enhances photodetection capability across a spectral region that spans the ultraviolet, visible and near infrared (UV-NIR). A low dark current density $\left(1.03 \times 10^{-6} \mathrm{~mA} / \mathrm{cm}^{2}\right)$, and a large specific detectivity of approximately $2.6 \times 10^{12} \mathrm{Jones}$ at a wavelength of $450 \mathrm{~nm}$ are demonstrated, significantly outperforming previously reported flexible QDs-based detectors. This improvement in performance is attributed to both increased hole transport efficiency, and the inhibition of electron transport from the QDs into PEDOT:PSS layer. The photodetector also exhibits good sensitivity under weak illumination, producing a photocurrent of $196 \times 10^{-6} \mathrm{~mA} / \mathrm{cm}^{2}$ under an irradiance of $5 \mu \mathrm{W} / \mathrm{cm}^{2}$. Moreover, no significant performance degradation is observed after 150 bending cycles to an angle of 60 degrees.
\end{abstract}

\section{Introduction}

Quantum dots (QDs) have drawn great attention due to their promising electronic and optoelectronic characteristics, ${ }^{1}$ for instance, widely tunable bandgap, ${ }^{2}$ large light absorption coefficient, ${ }^{3,4}$ and high photochemical stability. ${ }^{5}$ Furthermore, QDs can be easily synthesised and processed by solution-based methods. ${ }^{6}$ These significant properties have led to broad application, such as in solar cells, ${ }^{7-9}$ light-emitting diodes, ${ }^{10}$ lasers $^{11}$ and photodetectors. ${ }^{12}$ Specifically, photodetectors are widely applied in chemical sensing, light imaging, optical communications, industrial manufacturing, environmental monitoring and medical analysis. ${ }^{13-15}$ The quantum confinement effect in QDs increases the bandgap with reducing size, ${ }^{16}$ leading to low thermal excitation, and hence lower dark currents and higher operating temperatures. Therefore, QDs are recognized as promising materials for demanding photodetector applications. ${ }^{17-19} \quad$ Self-powered (i.e. photovoltaic) photodetectors typically have lower dark currents and faster response speeds than Schottky type devices, ${ }^{20}$ allowing them to operate at higher frequency with lower noise.

\footnotetext{
a. Institute for Advanced Materials and Technology, University of Science and Technology Beijing, Beijing, 100083, China.

E-mail: tianjianjun@mater.ustb.edu.cn

b. School of Physics and Astronomy and Photon Science Institute, University of

Manchester, Manchester, M13 9PL, UK.

c. Department of Materials and Engineering, University of Washington, Seattle, WA, 98195-2120, USA.

+ Electronic Supplementary Information (ESI) available: [details of any supplementary information available should be included here]. See DOI: $10.1039 / x 0 x x 00000 x$
}

Further, to realize intelligent electronic systems, there is an increasing demand to combine optoelectronic functionality with other characteristics that make a device more suited to applications ${ }^{21,} 22$ such as shock resistance, portability and flexibility. ${ }^{19,23,24}$ For instance, flexible devices can be attached to curved surfaces or skin or woven into garments to realize detection or optical communication. ${ }^{23,} 25$ Thus, a flexible selfpowered photodetector with broadband response, fast speed, high detectivity, excellent weak-light responsivity and stability would be well suited to many applications. However, the performance of flexible photodetectors is currently significantly worse than that of similar devices fabricated on glass substrates. In particular, the detectivity of flexible photodetectors is 10 times less than that of rigid devices with the same photosensitive materials and architecture. ${ }^{22,} 26$ Therefore, new designs are required for flexible photodetectors so that they can match the performance of rigid devices.

Bearing this in mind, a novel photodetector with a bulkheterojunction architecture comprising PEDOT:PSS/poly (N,N9bis(4-butylphenyl)-N,N9-bis(phenyl)-benzidine) TPD)/QDs/ZnO fabricated onto a flexible polyethylene terephthalate substrate is first demonstrated in this work. The double hole transport layer (HTL) of PEDOT:PSS and P-TPD used results in improved hole transport and enhances the detector response to UV-NIR light. Furthermore, P-TPD has a high-lying lowest unoccupied molecular orbital (LUMO) level which enables it to acts as an effective electron blocking layer, suppressing electron-hole recombination. Thus, enhanced UVNIR photodetection capability was obtained, with a detectivity $\left(D^{*}\right)$ of $2.6 \times 10^{12}$ Jones, detector responsivity (R) of $45 \mathrm{~mA} / \mathrm{W}$, high on-off ratio $\left(\mathrm{I}_{\mathrm{on}} / \mathrm{I}_{\text {off }}\right)$ of $9.9 \times 10^{5}$ under a power of 100 
$\mathrm{mW} / \mathrm{cm}^{2}$, and short rise/decay time $\left(\mathrm{t}_{\mathrm{r}} / \mathrm{t}_{\mathrm{d}}=40 \mathrm{~ms}\right)$. In addition, the double HTL-based photodetector displayed a high photocurrent response $\left(196 \times 10^{-6} \mathrm{~mA} / \mathrm{cm}^{2}\right)$ even under weak illumination $\left(5 \mu \mathrm{W} / \mathrm{cm}^{2}\right)$, making it well-suited for low light detection. Moreover, the flexible device demonstrated negligible degradation in performance after 150 bending cycles. Thus, a self-powered, flexible QD-based photodetector, with high specific detectivity, responsivity, durability and stability, has been demonstrated providing a promising route for the monitoring, diagnosis and imaging applications.

\section{Experimental}

\section{Synthesis Method}

Preparation of $\mathrm{Cd}$, Se, Te precursor: $0.411 \mathrm{~g}$ of $\mathrm{CdO}$ powder ( $0.0316 \mathrm{~g}$ of Se powder, $1 \mathrm{ml}$ TOP and $3 \mathrm{ml}$ paraffin liquid/0.038 $\mathrm{g}$ of Te powder, $0.75 \mathrm{ml}$ TOP and $2.25 \mathrm{ml}$ paraffin liquid) were loaded into $50 \mathrm{ml}$ 3-neck flask containing $24 \mathrm{ml}$ of paraffin liquid and $8 \mathrm{ml}$ of oleic acid, degassed for $40 \mathrm{~min}$ before $90{ }^{\circ} \mathrm{C}$, and subsequently heated up to $260{ }^{\circ} \mathrm{C}$ in a nitrogen atmosphere until all powders were dissolved and the solution became clear (for Se and Te precursor, the reaction temperature were $150{ }^{\circ} \mathrm{C}$, $300{ }^{\circ} \mathrm{C}$, respectively). The three precursor solution were stored in $\mathrm{N}_{2}$ at $50^{\circ} \mathrm{C}$ until it was needed for the QD synthesis.

The reaction mixture with a Cd:Se:Te molar ratio of 10:1:1 was stirred in a $100 \mathrm{ml}$-three-necked flask and degassed for $40 \mathrm{~min}$ at $90{ }^{\circ} \mathrm{C}$. The flask was purged with $\mathrm{N}_{2}$ and then placed back under vacuum. This process of alternately applying vacuum and $\mathrm{N}_{2}$ was repeated for a total of 3 times to remove $\mathrm{H}_{2} \mathrm{O}$ and $\mathrm{O}_{2}$. The flask was always in vacuum until no gas was released from the solution and then heated up to $310^{\circ} \mathrm{C}$ at a rate of $30^{\circ} \mathrm{C} / \mathrm{min}$ under nitrogen atmosphere along with vigorous stirring. After reacting for $3 \mathrm{~min}$, the reaction mixture was cooled to $260{ }^{\circ} \mathrm{C}$, and $2 \mathrm{ml}$ of oleylamine was swiftly injected into the solution to limit the growth of the nanocrystals. The solution was then allowed to cool to $60^{\circ} \mathrm{C}$ by removing the heater. $\mathrm{CdSe}_{\mathrm{x}} \mathrm{Te}_{1-\mathrm{x}} \mathrm{QDs}$ with a diameter of $5.1 \pm 0.2 \mathrm{~nm}$, were obtained after cleaning and purification.

\section{Device fabrication}

PEDOT:PSS solution was spin-coated at $4000 \mathrm{rpm}$ onto a cleaned ITO/PET substrate for $60 \mathrm{~s}$ and then heated up to 110 ${ }^{\circ} \mathrm{C}$, before transfer into a nitrogen-filled glove box after $20 \mathrm{~min}$. P-TPD, CdSe $\mathrm{Te}_{1-x} \mathrm{QDs}$ and $\mathrm{ZnO}$ solutions were spin-coated layer-by-layer at $2500 \mathrm{rpm}$ for $30 \mathrm{~s}$. The P-TPD layer was heated at $110^{\circ} \mathrm{C}$ for $20 \mathrm{~min}$ before the deposition of the next layer. The QDs layer and the $\mathrm{ZnO}$ layer were baked at $80^{\circ} \mathrm{C}$ for $20 \mathrm{~min}$. Al electrodes were deposited using a thermal evaporation system under vacuum of $\sim-10^{-4}$ torr.

\section{Device Characterization}

The absorption spectra of the colloidal $\mathrm{Cd}_{x} \mathrm{Se}_{1-x} T e$ QDs was measured by a UV-visible spectrophotometer (T10CS) over a wavelength range of $300 \mathrm{~nm}$ to $900 \mathrm{~nm}$. XRD measurements were performed with X-ray diffractometer (PANalytical EPSILON5) using monochromatic $\mathrm{Cu}$ K $\alpha$ radiation and a voltage of $30 \mathrm{kV}$ and a current of $30 \mathrm{~mA}$. The PL spectrum was acquired using a photoluminescence spectrometer (FL-380, Gangdong
Sci. \& Tech. Development Co., LTD, Tianjin, China) from $358, n m$

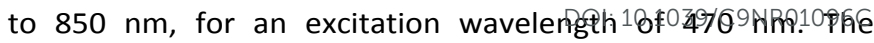
responsivity spectra were obtained in a direct current mode over the range $300 \sim 850 \mathrm{~nm}$. The measurement system is composed of Keithley 2400 multimeter as a digital source meter, a $150 \mathrm{~W}$ Xenon lamp and a 7 Star Optical Instruments 7ISW30 monochromator. An electrochemical workstation $(\mathrm{CH}$ Instruments, Inc., Shanghai, China) was employed for electrochemical impedance spectroscopy (EIS) and the photocurrent response under light switching was obtained using a 7150503A solar simulator (7 star Optical Instruments Co., Beijing, China) with an output intensity of $\sim 100 \mathrm{~mW} / \mathrm{cm}^{2}$. 3A grade AM 1.5 simulated sunlight with an output power of $\sim 100 \mathrm{~mW} / \mathrm{cm}^{2}$ was used to obtain the I-V characteristics of the devices. The SEM images were taken using a Hitachi SU8020 scanning electron microscope which incorporates an energydispersive X-ray (EDX) spectrometer. A Phoenix 600 Contact Angle Meter was employed to measure the contact angles. The TEM images were taken with a JEM-2010 transmission electron microscope.

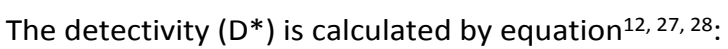

$$
D^{*}=\mathrm{R} \frac{1}{\sqrt{2 q I_{\text {dark }} / S}}
$$

where $\mathrm{R}$ is the responsivity, $I_{\text {dark }}$ is the dark current, $\mathrm{S}$ is the active area of the device, the active area is $0.1007 \mathrm{~cm}^{2}$, and $q$ is the elementary charge. For a self-powered detector, the shot noise from the dark current is the major contribution to the noise current, and arises from the change of the diffusion rate caused by random thermal movement and the random fluctuations of the carrier density caused by thermal generation-recombination. Thus the noise current can directly inferred from the dark current in self-powered detectors.

\section{Results and discussion}


The device structure of the flexible self-powered QD-based photodetector with single HTL and double HTL are displayed schematically in Figure $1 a$ and $b$, respectively. Here, p-type poly (N,N9-bis(4-butylphenyl)-N,N9-bis(phenyl)-benzidine) (P-TPD) was spin coated onto a PEDOT:PSS layer to form the double HTL. A cross-sectional scanning electron microscopy (SEM) image of the device with double HTL is shown in Figure 1c, which is stacked in the structural sequence of Al electrode/ZnO electron transport layer (ETL)/CdSe $\mathrm{Te}_{1-\mathrm{x}} \quad \mathrm{QDs}$ layer/PTPD/PEDOT:PSS/tin-oxide doped with indium/polyethylene terephthalate (ITO/PET). The transparency and flexibility of the device can be observed from the image inset in Figure 1c. The energy level diagram for the photodetector in Figure $1 \mathrm{~d}$ indicates that electrons are injected into the ZnO ETL, and holes are transported via the P-TPD and PEDOT:PSS double HTL. As can be seen from the energy band diagram, the energy gap between the highest occupied molecular orbital (HOMO) level of the P-TPD and the valence band maximum (VBM) of the $\mathrm{CdSe}_{x} \mathrm{Te}_{1-\mathrm{x}} \mathrm{QDs}$ is only $0.03 \mathrm{eV}$ and so facilitates hole injection. Moreover, the $1.3 \mathrm{eV}$ difference between the P-TPD LUMO level and the conduction band minimum (CBM) of the $\mathrm{CdSe}_{\mathrm{x}} \mathrm{Te}_{1-\mathrm{x}}$ QDs makes P-TPD an effective electron blocking material, inhibiting charge recombination and thereby improving device performance. However, the experimental results below indicate that the device with only one layer of P-TPD as the HTL has comparatively poor performance, likely due to the large difference between the VBM of ITO and the LUMO level of PTPD. (a)

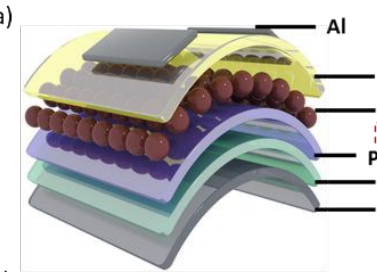

(c)

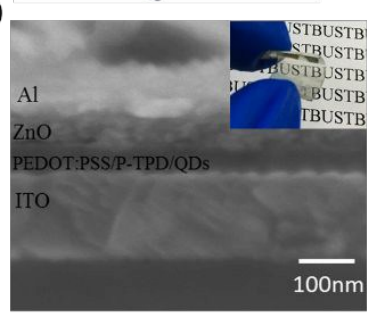

(e)

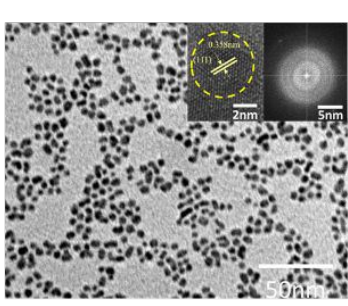

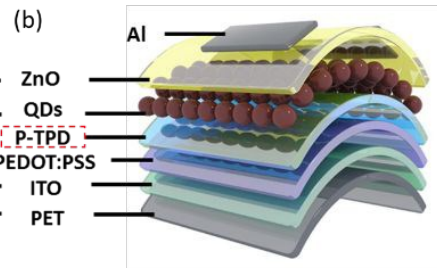

(d)

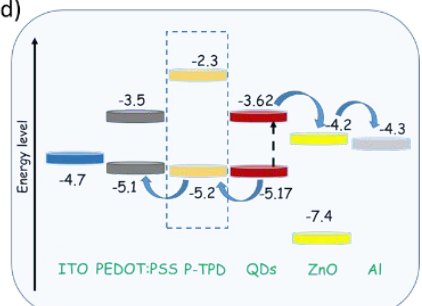

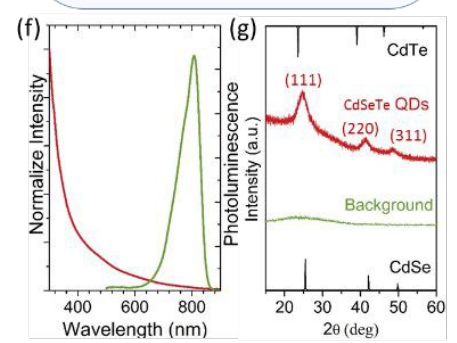

Figure 1. Schematic diagram of the devices with single HTL layer (a) and double HTL layer (b), respectively. (c) Cross-sectional SEM image with an image of the device inset, and (d) energy band diagram of the photodetector with double HTL layer. (e) TEM image, with HRTEM and SAED images inset, (f) absorption (red line) and steady-state photoluminescence $(\mathrm{PL})$ spectra (green line, $\lambda_{\mathrm{ex}}=470 \mathrm{~nm}$ ) and $(\mathrm{g}) \mathrm{X}$-ray diffraction (XRD) pattern of the $\mathrm{CdSe}_{\mathrm{x}} \mathrm{Te}_{1-\mathrm{x}} \mathrm{QDs}$.
Transmission electron microscopy (TEM) of the Acelloidal $\mathrm{CdSe}_{\mathrm{x}} \mathrm{Te}_{1-\mathrm{x}} \mathrm{QDs}$, see Figure 1e, was used toodeteerminine theirosize and shape and shows them to be of nearly spherical shape with a narrow size distribution (without any post-preparation fractionation or size sorting) and have an average particle size of $5.1 \pm 0.2 \mathrm{~nm}$. (The composition of $\mathrm{CdSe}_{x} \mathrm{Te}_{1-\mathrm{x}}$ is close to $\mathrm{CdSe}_{0.67} \mathrm{Te}_{0.33}$, which is confirmed by EDX as shown in Figure $\mathrm{S} 1$ ). The inset in Figure 1e shows a high resolution TEM (HRTEM) image of a QD, in which the lattice fringes for $\mathrm{CdSe}_{x} \mathrm{Te}_{1-\mathrm{x}}$ are clearly evident in the selected area electron diffraction (SAED) pattern, indicating good crystallinity. The lattice spacing of $0.358 \mathrm{~nm}$, as shown in the HRTEM image, is in good agreement with the values for the (111) plane for both zinc blend CdSe (JPCDS card no. 19-0191, lattice spacing: $0.351 \mathrm{~nm}$ ) and CdTe (JPCDS card no. 65-1081, lattice spacing: $0.374 \mathrm{~nm}$ ). Figure $1 \mathrm{f}$ shows the absorption and steady-state photoluminescence (PL) spectra for the $\mathrm{CdSe}_{\mathrm{x}} \mathrm{Te}_{1-\mathrm{x}} \mathrm{QDs}$. The onset of absorption is at about $800 \mathrm{~nm}$ while the PL peak is centred at $810 \mathrm{~nm}$, demonstrating the NIR band edge of the QDs. It thus possesses a light harvesting range well-matched to the solar spectrum and the emission of artificial lighting. The $\mathrm{X}$-ray diffraction (XRD) pattern shown in Figure $1 \mathrm{~g}$ confirms the presence of $\mathrm{CdSe} \mathrm{Te}_{\mathrm{x}}$ QDs. The sample exhibits the well-resolved diffraction peaks characteristic of $\mathrm{CdSe}_{\mathrm{x}} \mathrm{Te}_{1-\mathrm{x}}$. In particular, it has strong peaks at $24.7^{\circ}$ and $41.4^{\circ}$, which lie between the standard values for zinc blende CdSe (JPCDS card no. 19-0191) and CdTe (JPCDS card no. 65-1081). It is thus consistent with the TEM analysis. The wide diffraction peaks are attributed to the small size of the QDs. ${ }^{16,29}$

Figure 2a compares the current-voltage (I-V) response for devices fabricated with single HTL and double HTL (the performance of the two devices without QD-photodetector incorporating a double PEDOT:PSS/P-TPD HTL structure was fabricated via solution-processing methods onto a flexible substrate. By the addition of P-TPD to form a double HTL, the hole transport efficiency was significantly enhanced. Due to the
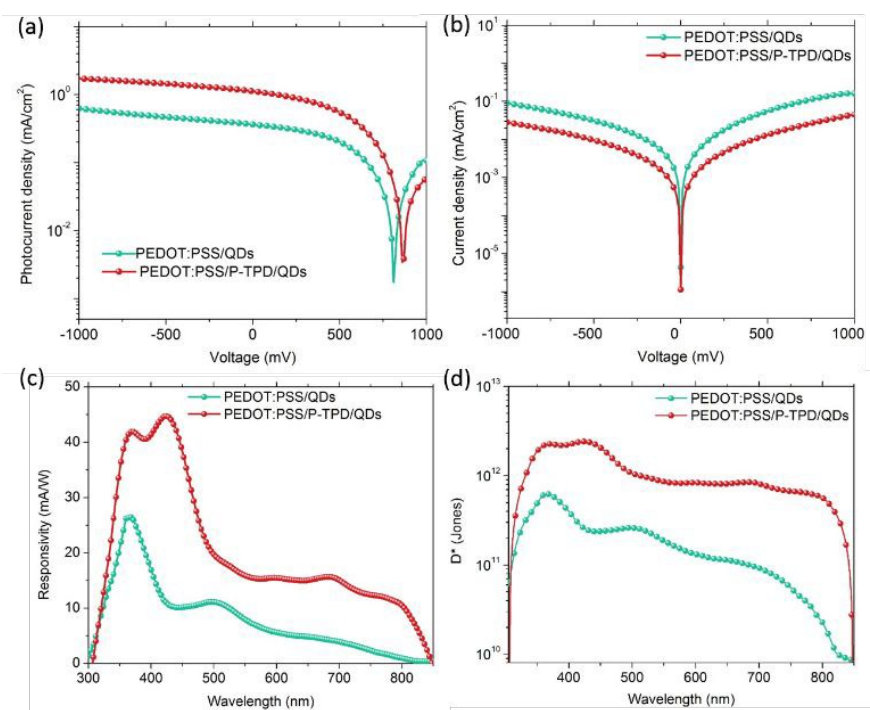

Figure 2 Current-voltage characteristic under white light illumination of 100 $\mathrm{mW} / \mathrm{cm}^{2}$ (a) and in the dark (b). Responsivity (c) and detectivity (d) of the single HTL and double HTL devices under a bias of $0 \mathrm{~V}$ as a function of wavelength (from $300 \mathrm{~nm}$ to $850 \mathrm{~nm}$ ). 
(a)

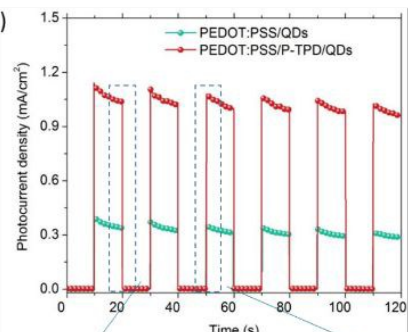

(b)

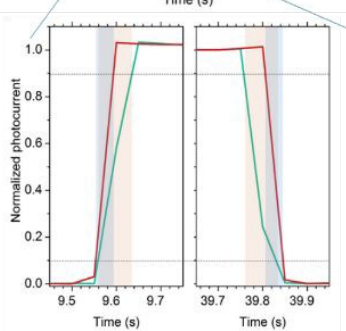

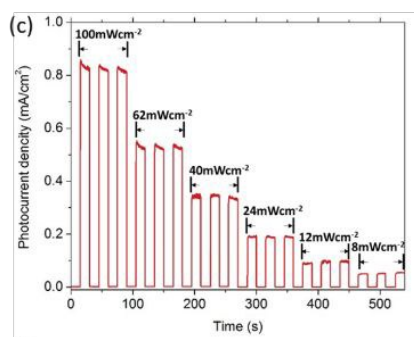

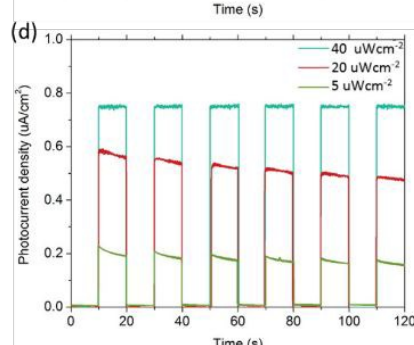

Figure 3. (a) Current response of the devices under white light switching at $100 \mathrm{~mW} / \mathrm{cm}^{2}$. (The blue dash line refers to the selected location of the magnified area below in the Figure $3 b$ ). (b) Single normalized switching characteristics of two devices to estimate response time at zero bias under white light illumination (at $100 \mathrm{~mW} / \mathrm{cm}^{2}$ ). (c) The photocurrent density of the device with double HTL under different optical powers. (d) The photocurrent density of the device under weak light at zero bias. The incident white light ranged in power from $40 \mu \mathrm{W} / \mathrm{cm}^{2}$ to $5 \mu \mathrm{W} / \mathrm{cm}^{2}$.

high LUMO energy level of the P-TPD, electron transportitto, the

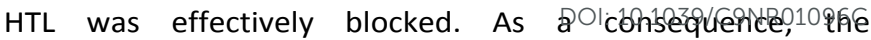
photodetector exhibited a broad spectral response encompassing the ultraviolet-visible-near infrared (UV-NIR) region, a high specific detectivity of $2.6 \times 10^{12}$ Jones, a fast response speed of $40 \mathrm{~ms}$, and a high responsivity of $45 \mathrm{~mA} / \mathrm{W}$ with extreme flexibility. The detectivity is higher that of the reported flexible QD-photodetectors, and is comparable to rigid devices with same architecture. More importantly, an excellent photocurrent density $\left(196 \times 10^{-6} \mathrm{~mA} / \mathrm{cm}^{2}\right)$ was observed for the double HTL-based photodetector under weak light illumination $\left(5 \mu \mathrm{W} / \mathrm{cm}^{2}\right)$. The flexible device also showed excellent folding endurance and electrical stability after bending 150 cycles. Our results suggest that such high-performance flexible photodetector may have great potential for monitoring, communications and imaging applications. $\mathrm{CdSe}_{\mathrm{x}} \mathrm{Te}_{1-\mathrm{x}} \mathrm{QDs}$ were also tested; more details can be found in Figure S2 of Supporting Information), from which excellent rectifying behaviors can be observed for the both devices. The double HTL-based detector shows significantly higher photocurrent density $\left(1.12 \mathrm{~mA} / \mathrm{cm}^{2}\right)$ than the single $\mathrm{HTL}$-based devices $\left(0.37 \mathrm{~mA} / \mathrm{cm}^{2}\right)$. A rectification ratio as high as $9.9 \times 10^{5}$ was found for the double HTL-based device, and its open-circuit voltage was measured to be $0.78 \mathrm{~V}$ (The optimization of the devices are shown in Figure S3 and S4). This can be ascribed to fast hole transport and effective suppression of charge recombination. The mobility of holes in P-TPD $\left(1.0 \times 10^{-4} \mathrm{~cm}^{2} \mathrm{~V}^{-1} \mathrm{~s}^{-1}\right)$ is more than two times higher than that of PEDOT:PSS $\left(4.0 \times 10^{-5} \mathrm{~cm}^{2} \mathrm{~V}^{-1} \mathrm{~s}^{-1}\right) \cdot{ }^{30}$ In addition, the large band offset of $1.3 \mathrm{eV}$ (see Figure $1 \mathrm{~b}$ ) constitutes an effective barrier to electron transport from the QDs to PEDOT:PSS, reducing charge recombination. Such a reduction in recombination can lead to a high photocurrent and low dark current density. ${ }^{31}$ The lower dark current density for the device with double HTL, as shown in Figure $2 b$, demonstrates that this design can significantly decrease the leakage of current. The lower dark current will also result in a faster response speed and high detectivity. ${ }^{32,33}$ Responsivity $(R)$ is a measure of the current output per optical input and is a key factor that determines the device sensitivity. ${ }^{34,35}$ From Figure $2 c$, the responsivities of the double HTL-based device for excitation at wavelengths of 350 $\mathrm{nm}, 450 \mathrm{~nm}$ and $800 \mathrm{~nm}$ at a power of $100 \mathrm{~mW} / \mathrm{cm}^{2}$ are 37.0 , 41.5 and $10.5 \mathrm{~mA} / \mathrm{W}$, respectively, which are $1.8,4.0$ and 3.5 times larger than those of the single HTL-based device. In addition, the photoresponsivity spectra correspond to the absorption spectra of the $\mathrm{CdSe}_{\mathrm{x}} \mathrm{Te}_{1-\mathrm{x}}$ QDs in Figure 1f. The detectivity $\left(D^{*}\right)^{36-41}$ characterises the ability of photodetectors to detect light, and the $D^{*}$ spectra for the single and double devices are compared in Figure $2 \mathrm{~d}$. It is worth noting that the double HTL-based photodetector exhibits larger $D^{*}$ than that of the single HTL-based photodetector across the entire wavelength range of $300 \sim 850 \mathrm{~nm}$. The D* of the double HTLbased device is up to $2.1 \times 10^{12}$ Jones at $350 \mathrm{~nm}, 2.6 \times 10^{12}$ Jones at $450 \mathrm{~nm}$ and $0.5 \times 10^{12}$ Jones at $800 \mathrm{~nm}$. These values are larger than that of previously reported flexible QDs photodetectors, as summarized in Table S1. Furthermore, rigid photodetectors with the same structure were prepared for comparison with the flexible devices. The properties of the devices based on the rigid 
and flexible substrates are listed in Table S2, and demonstrate that flexible photodetectors can have comparable performance to those based on rigid substrates. This enhanced performance for a flexible device is attributed to the introduction of double $\mathrm{HTL}$, which greatly enhances the charge collection efficiency of the device.

Reliability and response speed are often crucial parameters for photodetectors. ${ }^{42-44}$ The on-off switching properties of both devices are shown in Figure 3 a (under $3 \mathrm{~A}$ grade illumination power of $100 \mathrm{~mW} / \mathrm{cm}^{2}$ ). It is seen that the photocurrent remains nearly constant after six cycles of light switching, showing that both devices can be switched on and off repeatedly. The photocurrent rapidly reaches saturation under this illumination, and then drops quickly with the light off. This indicates that the device allows facile charge tunnelling and transportation. It is worth noting that the photocurrent density decreases with increasing time. A possible reason for this observation is that the carriers are rapidly generated by the light excitation to produce high current. These carriers are then gradually trapped, resulting in a reduction in the current until the traps are completely filled. Figure $3 b$ shows the more detailed transient photocurrent of the device, where one on-off cycle is shown. The rise and decay times, $t_{r}$, and $t_{d}$, respectively, for the double HTL-based device are both $40 \mathrm{~ms}$, which is half the value obtained for the single HTL-based device (i.e. $80 \mathrm{~ms}$ ). The greater response speed of the double HTL-based device could be associated with faster carrier separation, a greater hole transport rate and a decrease in charge recombination in the device. The temporal evolution of $\mathrm{V}_{\mathrm{oc}}$ for both detectors is shown in Figure S5. The double HTL-based photodetector possesses higher voltage output and faster voltage response speed than that of single HTL-based photodetector. Light intensity-dependent measurements of photocurrent were employed to explore the response of the photodetector. Figure $3 \mathrm{c}$ shows the photocurrent of the double HTL-based photodetector under different light intensities. The photocurrent of the devices is about $0.056 \mathrm{~mA} / \mathrm{cm}^{2}$ under low light intensity $\left(8 \mathrm{~mW} / \mathrm{cm}^{2}\right)$. We can observe good linear response of the device to light intensity for a decrease from 100 $\mathrm{mW} / \mathrm{cm}^{2}$ to $8 \mathrm{~mW} / \mathrm{cm}^{2}$. The current levels remain nearly constant for three cycles under different light intensities. The $3 \mathrm{~dB}$ bandwidth of a photodetectors is an important parameter to typically determine the temporal response. Both the carrier lifetime and the resistance-capacitance time of the circuit can determine the $3 \mathrm{~dB}$ bandwidth of the photodetector, ${ }^{21}$ which is $200 \mathrm{~Hz}$ for the photodetector with double HTL as shown in Figure S6, indicating good frequency response. To explore the capability of the device for weak light detection, the photocurrent density of the devices (under light switching) were detected at weak irradiances, as shown in Figure 3d. We found that the generated photocurrent density was about $196 \times 10^{-6} \mathrm{~mA} / \mathrm{cm}^{2}$ for a light power of $5 \mu \mathrm{W} / \mathrm{cm}^{2}$, which was hundredfold higher than the dark current. Note that the photodetector with single HTL does not show such high sensitivity and requires a minimum light strength of 100 $\mu \mathrm{W} / \mathrm{cm}^{2}$ for detection as shown in Figure S7. The double HTL device also performs well in the weak-light response compared

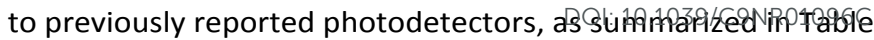
S3. The response of the device to weak illumination is likely made possible for two main reasons. On one hand, the P-TPD layer could be enhancing photodetection in the visible part of the spectrum (the absorbance curves of films with PEDOT:PSS and PEDOT:PSS/P-TPD are compared in Figure S8 of Supporting Information). On the other hand, P-TPD can facilitate the separation of the carriers, improve hole transport and enhance charge collection. This device thus has a great potential in the field of weak light detection. It should be note that the photodetector has a good reproducibility with small standard deviation as shown in Figure S9. The average values of twelve devices for $R$ is $40.10 \pm 5.95 \mathrm{~mA} / \mathrm{W}$ and for $D^{*}$ is $(2.30 \pm 0.35) \times$ $10^{12}$ Jones. The enhanced $R$ and $D^{*}$, the higher on/off ratio, the outstanding response under the weak light and the fast light response for the double HTL-based device in comparison to that
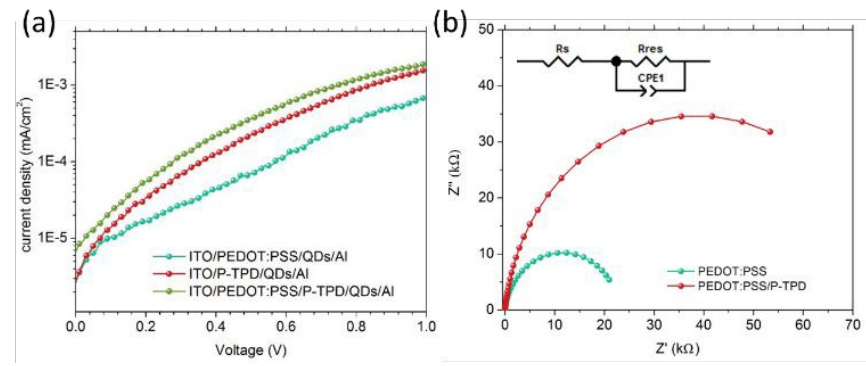

Figure 4. (a) The dependence of dark current density on bias voltage for hole-only versions of the three devices (ITO/PEDOT:PSS/QDs/Al, ITO/P-TPD/QDs/Al and ITO/PEDOT:PSS/P-TPD/QDs/AI). (b) The electro-chemical impedance spectroscopy (EIS) spectrums of the devices with PEDOT:PSS and PEDOT:PSS/P-TPD layer in the dark conditions at a bias voltage equivalent to the open voltage of the devices. Inset: equivalent circuit.

of the single HTL-based device are all originated from the decreased charge recombination, increased photon harvesting and fast charge transfer.

To determine the transport properties, the I-V curves for holeonly versions of the devices were measured under dark conditions, as shown in Figure 4a. The hole-only devices are composed of ITO/PEDOT:PSS/QDs/AI, ITO/P-TPD/QDs/Al and ITO/PEDOT:PSS/P-TPD/QDs/Al, respectively. Improved hole transport is demonstrated by higher current in the hole-only devices, which is determined by the product of the mobility, the steady-state charge density and carrier lifetime in a film. ${ }^{41,45}$ The current densities of both ITO/P-TPD/QDs/AI and ITO/PEDOT:PSS/P-TPD/QDs/Al are significantly larger than that of ITO/PEDOT:PSS/QDs/Al. It suggests that the P-TPD can effectively facilitate the hole transport into PEDOT:PSS and boost carrier collection. To explore the charge blocking capacity of the P-TPD layer on charge recombination, electrochemical impedance spectroscopy (EIS) was carried out. Figure $4 \mathrm{~b}$ displays the Nyquist plot of two devices at an applied bias equal to the open circuit voltage under dark conditions. In Figure $4 b$, each semicircle characterizes the charge transport at the interface of the device, and can be represented by an equivalent circuit (inset of Figure $4 b$ ) that consists of $R_{r e d} / C P E$ and $R_{s}$. Here, $R_{\text {rec }}$ and CPE represent the impedance related to the charge 
transfer process and the interface capacitance, respectively. $R_{s}$ indicates the series resistance of the entire device, which includes contributions from the conductive glass, wires and the interface of the device. ${ }^{45,46}$ The double HTL-based device has a $R_{\text {rec }}$ of $76.3 \mathrm{k} \Omega$, whereas the single HTL-based device has the smaller value of $12.1 \mathrm{k} \Omega$. $\mathrm{R}_{\text {rec }}$ reflects the ability to block charge recombination, which has an inversely-proportional relation with the recombination rate. ${ }^{47-49}$ The increase of $R_{\text {rec }}$ thus indicates that there is a higher charge collection efficiency for devices with a double HTL. The P-TPD layer will inhibit recombination both by enhancing the separation and drift velocity of the electrons and holes, and by forming an effective energy barrier with its high HOMO level $(-2.6 \mathrm{eV})$, preventing backflow of electrons. Moreover, the effect of the P-TPD layer on the solution wettability was investigated by contact angle measurements. The contact angles measured for an octane solution of QDs on the surface of PEDOT:PSS and PEDOT:PSS/PTPD are $11.8^{\circ}$ and $9.9^{\circ}$, respectively, as shown in Figure $S 10$. The results indicate that wettability of the QD solution is similar on both surfaces, and thus that the thickness of the QD film has not been significantly affected by the P-TPD layer. ${ }^{50,51}$ Therefore, the enhanced photodetection capability of the double HTLbased photodetector is attributed to efficient hole transport in the P-TPD layer, and the inhibition of electron transport from the QDs into the PEDOT:PSS layer, rather than a change in the thickness of the active layer ( $\mathrm{CdSe}_{\mathrm{x}} \mathrm{Te}_{1-\mathrm{x}} \mathrm{QD}$ film).

To further consider the stability of these devices as flexible photodetectors in practical applications, the effect of device folding on the electrical performance was investigated. Figure 5a presents the steady-state photocurrent of the flexible devices with double HTL at various bending curvatures under a light intensity of $100 \mathrm{~mW} / \mathrm{cm}^{2}$. The optical images of the devices subjected to various bending angles are displayed in the insets of Figure 5a. In this study, four different bending states were studied: I (0 degree), II (20 degree), III (40 degree) and IV (60 degree). It can be seen that no obvious degradation in performance is detected in any of the four states for a photocurrent density of $0.98 \mathrm{~mA} / \mathrm{cm}^{2}$ over $250 \mathrm{~s}$, demonstrating the outstanding photocurrent stability of the device, which is unaffected by external bending stress. The photocurrent response of the devices under light periodically switched on and off was also tested for the four bending states as shown in Figure $5 \mathrm{~b}$. The photocurrent of the flexible photodetector also remains nearly constant in these four bending states. It exhibits the similar response time even after the IV bending state as shown in Figure S11. In order to assess folding endurance, the electrical performance of the photodetector was measured after bending the devices through mulitple cycles. The plots in Figure $5 \mathrm{c}$ are the I-V characteristics of the photodetector after bending through as many as 150 cycles. It should be noted that the photocurrent still remains of the same order after folding the device through 150 cycles. After more than 300 cycles, it shows a decrease trend for the photocurrent and photovoltage for the devices. And the decrease becomes obvious after 500 cycles. In addition, SEM images were used to evaluate any morphology changes of the films after different numbers of 
folding cycles. As shown in Figure $5 e$ and $f$, there are no microcracks or fissures evident in the films after folding for 50 or 150 cycles, and after folding a morphology is observed that is similar to the film before folding (Figure $5 \mathrm{~d}$ ). The atomic force
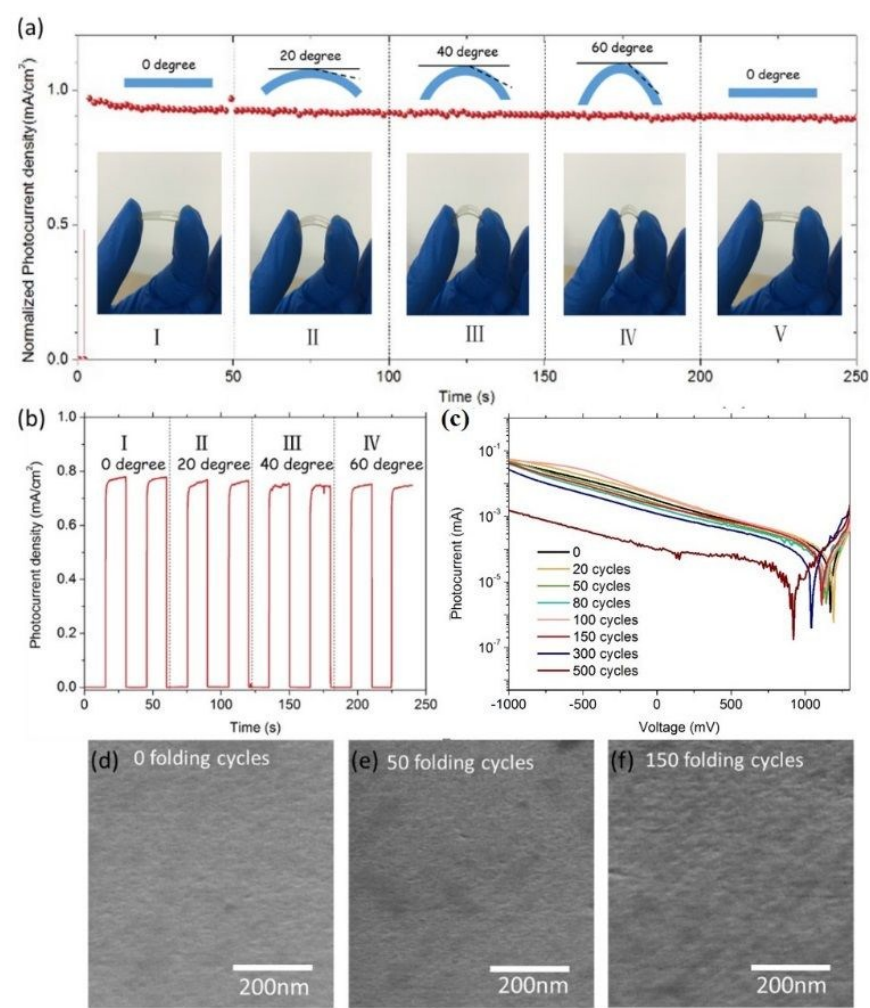

Figure 5. Photocurrent response of the double HTL device under (a) under constant illumination and (b) under switched light. (c) I-V characteristics of the flexible device after folding $0,20,50,80,100,150,300$ and 500 cycles. Measurements were made under a light intensity of $100 \mathrm{~mW} / \mathrm{cm}^{2}$. SEM images displaying the surface morphology of PEDOT:PSS/P-TPD/QDs/ZnO films after being subjected to (d) 0 folding cycles, (e) 50 folding cycles and (f) 150 folding cycles.

microscopy (AFM) images and corresponding surface roughness of the films are shown in Figure S12. After bending 500 cycles, the surface roughness increased corresponds to the decrease of photocurrent for the devices. These results demonstrate the flexible double HTL-based QD photodetectors have good mechanical and electrical stability.

\section{Conclusion}

A QD-photodetector incorporating a double PEDOT:PSS/P-TPD HTL structure was fabricated via solution-processing methods onto a flexible substrate. By the addition of P-TPD to form a double $H T L$, the hole transport efficiency was significantly enhanced. Due to the high LUMO energy level of the P-TPD, electron transport to the HTL was effectively blocked. As a consequence, the photodetector exhibited a broad spectral response encompassing the ultraviolet-visible-near infrared (UV-NIR) region, a high specific detectivity of $2.6 \times 10^{12}$ Jones, a fast response speed of $40 \mathrm{~ms}$, and a high responsivity of 45 $\mathrm{mA} / \mathrm{W}$ with extreme flexibility. The detectivity is higher that of the reported flexible QD-photodetectors, and is comparable to rigid devices with same architecture. More importantly, an excellent photocurrent density $\left(196 \times 10^{-6} \mathrm{~mA} / \mathrm{cm}^{2}\right)$ was

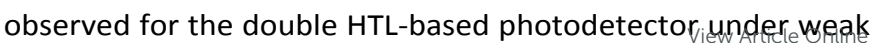
light illumination $\left(5 \mu \mathrm{W} / \mathrm{cm}^{2}\right)$. The flexibPe devicés alsonshowea excellent folding endurance and electrical stability after bending 150 cycles. Our results suggest that such highperformance flexible photodetector may have great potential for monitoring, communications and imaging applications.

\section{Conflicts of interest}

There are no conflicts to declare.

\section{Acknowledgements}

National Science Foundation of China (51961135107, 51774034, 51772026), National Key Research and Development Program of China (2017YFE0119700), and Beijing Natural Science Foundation (2182039).

\section{References}

1 X. Peng, Nano Research, 2010, 2, 425-447.

2 S. Ruhle, M. Shalom, A. Zaban, Chem. Phys. Chem. 2010, 11, 2290-2304

3 W. W. Yu, L. QU, W. Guo, X. Peng, Chem. Mater. 2003, 15, 2854-2860.

4 G. H. Carey, A. L. Abdelhady, Z. Ning, S. M. Thon, O. M. Bakr, E. H. Sargent, Chem. Rev. 2015, 115, 12732-12763.

5 M. R. Kim, D. Ma, J. Phys. Chem. Lett. 2015, 6, 85-99.

6 J. Y. Kim, O. Voznyy, D. Zhitomirsky, E. H. Sargent, Adv. Mater. 2013, 25, 4986-5010.

7 E. H. Sargent, Nature Photon. 2012, 6, 133-135.

8 T. Shen, J. J. Tian, L. L. Lv, C. B. Fei, Y. J. Wang, T. Pullerits, G. Z. Cao, Electrochim. Acta 2016, 191, 62-69.

9 J. Tian, L. Lv, C. Fei, Y. Wang, X. Liu, G. Cao, J. Mater. Chem. A 2014, 2, 19653-19659.

10 R. S. Sanchez, M. S. d. I. Fuente, I. Suarez, G. Muñoz-Matutano, J. P. Martinez-Pastor, Science, 2016, 2, e1501104.

11 G. Walter, N. Holonyak, R. D. Heller, R. D. Dupuis, Appl. Phys. Lett. 2002, 81, 4604-4606.

12 V. Adinolfi, O. Ouellette, M. I. Saidaminov, G. Walters, A. L. Abdelhady, O. M. Bakr, E. H. Sargent, Adv. Mater. 2016, 28, 7264-7268.

13 D. Kufer, I. Nikitskiy, T. Lasanta, G. Navickaite, F. H. Koppens, G. Konstantatos, Adv. Mater. 2015, 27, 176-180.

14 Y. Wang, D. Yang, X. Zhou, D. Ma, A. Vadim, T. Ahamad, S. M. Alshehri, Adv. Opt. Mater. 2017, 5, 1700213.

15 C. Bao, J. Yang, S. Bai, W. Xu, Z. Yan, Q. Xu, J. Liu, W. Zhang, F. Gao, Adv. Mater. 2018, 30, e1803422.

16 R. E. Bailey, S. Nie, J. Am. Chem. Soc. 2003, 125, 7100-7106.

17 M. S. Park, V. Jain, W. J. Choi, H. Pettersson, Q. Wang, J. D. Song, E. H. Lee, S. H. Kim, Electron. Lett. 2014, 50, 1731-1733.

18 P. Martyniuk, A. Rogalski, Bull. Pol. Aca. Sci: Tech Sci. 2009, 57, 103.

19 P. Martyniuk, A. Rogalski, Prog. Quant. Electron. 2008, 32, 89120.

20 L. -B. Luo, J. -J. Chen, M. -Z. Wang, H. Hu, C. -Y. Wu, Q. Li, L. Wang, J. -A. Huang, F. -X. Liang, Adv. Funct. Mater. 2014, 24, 2794-2800.

21 F. P. García de Arquer, A. Armin, P. Meredith, E. H. Sargent, Nat. Rev. Mater. 2017, 2, 16100.

22 M. Peng, Y. Wang, Q. Shen, X. Xie, H. Zheng, W. Ma, Z. Wen, X. Sun, Sci. China Mater. 2019, 62, 225-235. 
23 V. Q. Dang, G. -S. Han, T. Q. Trung, L. T. Duy, Y. -U. Jin, B. U. Hwang, H. -S. Jung, N. -E. Lee, Carbon 2016, 105, 353-361.

24 S. Mitra, A. Aravindh, G. Das, Y. Pak, I. Ajia, K. Loganathan, E. Di Fabrizio, I. S. Roqan, Nano Energy, 2018, 48, 551-559.

25 W. S. Lee, S. W. Lee, H. Joh, M. Seong, H. Kim, M. S. Kang, K. H. Cho, Y. M. Sung, S. J. Oh, Small, 2017, 1702534.

26 I. Ka, L. F. Gerlein, L. M. Asuo, R. Nechache and S. G. Cloutier, Nanoscale, 2018, 10, 9044-9052.

27 X. Gong, M. Tong, Y. Xia, W. Cai, J. Moon, Y. Cao, G. Yu, C.-L. Shieh, B. Nilsson, A. J. Heeger, Science, 2009, 325, 1665-1668.

28 X. Yi, Z. Ren, N. Chen, C. Li, X. Zhong, S. Yang, J. Wang, Adv. Electron. Mater. 2017, 3, 1700251.

29 S. Wang, C. Bi, J. Yuan, L. Zhang, J. Tian, ACS Energy Lett. 2018, 3, 245-251.

30 X. Z. Dai, Z. Jin, Y. Niu, Y. Cao, H. Liang, X. Chen, L. Wang, X. Peng, Nature, 2014, 515, 96-110.

31 S. Pradhan, A. Stavrinadis, S. Gupta, S. Christodoulou, G. Konstantatos, ACS Energy Lett. 2017, 2, 1444-1449.

32 T. Shen, B. Li, K. Zheng, T. Pullerits, G. Cao, J. Tian, J. Phys. Chem. Lett. 2018, 9, 3285-3294.

33 Z. Ren, J. Sun, H. Li, P. Mao, Y. Wei, X. Zhong, J. Hu, S. Yang, J. Wang, Adv. Mater. 2017, 29, 1702055.

34 Y. Li, Y. Li, J. Shi, H. Zhang, J. Wu, D. Li, Y. Luo, H. Wu, Q. Meng, Adv. Funct. Mater. 2018, 1705220.

35 H. Bai, T. Shen, J. Tian, J. Mater. Chem. C, 2017, 5, 1054310548.

36 G. Maculan, A. D. Sheikh, A. L. Abdelhady, M. I. Saidaminov, M. A. Haque, B. Murali, E. Alarousu, O. F. Mohammed, T. Wu, O. M. Bakr, J. Phys. Chem. Lett. 2015, 6, 3781-3786.

37 D. C. Oertel, M. G. Bawendi, A. C. Arango, V. Bulović, Appl. Phys. Lett. 2005, 87, 213505.

38 R. Guo, T. Shen, J. Tian, J. Mater. Chem. C, 2018, 6, 2573-2579.

39 Z. Zheng, F. Zhuge, Y. Wang, J. Zhang, L. Gan, X. Zhou, H. Li, T. Zhai, Adv. Funct. Mater. 2017, 27, 1703115.

40 K. S. Cho, K. Heo, C. W. Baik, J. Y. Choi, H. Jeong, S. Hwang, S. Y. Lee, Nat. Commun. 2017, 8, 840.

41 F. Guo, B. Yang, Y. Yuan, Z. Xiao, Q. Dong, Y. Bi, J. Huang, Nature Nanotech. 2012, 7, 798-802.

42 S. F. Leung, K. T. Ho, P. K. Kung, V. K. S. Hsiao, H. N. Alshareef, Z. L. Wang, J. H. He, Adv. Mater. 2018, 27, 1704611.

43 Z. Gao, W. Jin, Y. Zhou, Y. Dai, B. Yu, C. Liu, W. Xu, Y. Li, H. Peng, Z. Liu, L. Dai, Nanoscale, 2013, 5, 5576-5581.

44 Y. Wei, Z. Ren, A. Zhang, P. Mao, H. Li, X. Zhong, W. Li, S. Yang, J. Wang, Adv. Funct. Mater. 2018, 28, 1706690.

45 J. Li, Z. Liang, Q. Su, H. Jin, K. Wang, G. Xu, X. Xu, ACS Appl. Mater. Interfaces, 2018, 10, 3865-3873.

46 C. Fei, L. Guo, B, Li, R. Zhang, H. Fu, J. Tian, G. Cao, Nano energy, 2017, 27, 17-26.

47 M. Li, B. Li, G. Cao, J. Tian, J. Mater. Chem. A, 2017, 5, 2131321319.

48 T. Shen, B. Li J. Tian, G. Cao, Sci. China Mater. 2016, 59, 833841.

49 J. Tian, E. Uchaker, Q. Zhang, G. Cao, ACS Appl. Mater. Interfaces, 2014, 6, 4466-4472.

50 A. Castan, H. M. Kim, J. Jang, ACS Appl. Mater. Interfaces, 2014, 6, 2508-2515.

51 M. -H. Lee, L. Chen, N. Li, F. Zhu, J. Mater. Chem. C, 2017, 5, 10555-10561. 
TOC

View Article Online 39/C9NR01096C

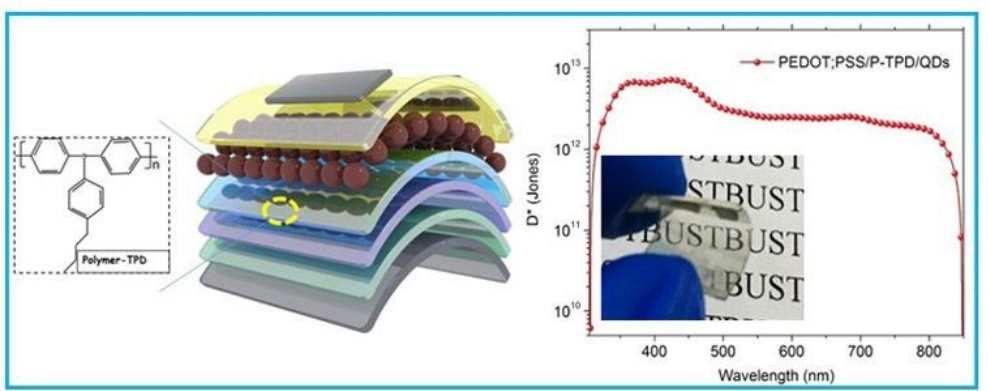

A flexible quantum dot photodetectors with large specific detectivity, excellent weaklight responsivity, outstanding mechanical and electrical stability, were successfully fabricated. 